\title{
Enhanced susceptibility to apoptosis of oral squamous cell carcinoma cells subjected to combined treatment with anticancer drugs and phosphatidylinositol 3-kinase inhibitors
}

\author{
MASAYASU IWASE, SAYAKA YOSHIBA, MAKIKO UCHID, SAYAKA TAKAOKA, \\ YUJI KURIHARA, DAISUKE ITO, MASASHI HATORI and SATORU SHINTANI \\ Department of Oral and Maxillofacial Surgery, Showa University School of Dentistry, \\ 2-1-1 Kitasenzoku, Ota-ku, Tokyo 145-8515, Japan
}

Received May 7, 2007; Accepted July 16, 2007

\begin{abstract}
The purpose of this study was to determine whether phosphatidylinositol 3-kinase (PI 3-K) inhibitors could modulate the apoptotic activity of the anticancer drugs cisplatin, 5-fluorouracil or docetaxel in an oral squamous cell carcinoma (OSCC) cell line, HSC-2. In preliminary experiments, cisplatin, 5-fluorouracil and docetaxel inhibited the proliferation of OSCC cells in a dose-dependent manner. We found that two PI 3-K inhibitors, wortmannin and LY294002, markedly suppressed the phosphorylation of Akt in OSCC cells. Treatment of OSCC cells with PI 3-K inhibitors significantly enhanced cisplatin-, 5-fluorouracil- or docetaxelinduced apoptosis. Caspase- 3 and -9 inhibitors, but not a caspase- 8 inhibitor, reduced anticancer drug-mediated apoptosis in PI 3-K inhibitor-treated OSCC cells, suggesting that the apoptotic pathway induced by the combination of anticancer drug therapy and PI 3-K inhibition may be functionally related to the intrinsic apoptotic pathway in OSCC cells. Expression of Bcl-2, cellular inhibitor of apoptosis protein-1 (cIAP-1), and X-linked IAP was down-regulated, and expression of Bax was up-regulated by PI 3-K inhibitors, while that of Bcl-xL, Bak and cIAP-2 was not attenuated. We also found that Bad phosphorylation was down-regulated by PI 3-K inhibitors. These results suggested that inhibition of PI 3-K enhances the susceptibility of OSCC cells to anticancer drug-mediated apoptosis through regulation of expression and post-translational modification of both pro- and antiapoptotic proteins. These findings could potentially lead to new strategies for improving the efficacy of anticancer drugs in OSCC cells.
\end{abstract}

Correspondence to: Dr Masayasu Iwase, Department of Oral and Maxillofacial Surgery, Showa University School of Dentistry, 2-1-1 Kitasenzoku, Ota-ku, Tokyo 145-8515, Japan

E-mail: iwase@senzoku.showa-u.ac.jp

Key words: anticancer drug, apoptosis, phosphatidylinositol 3-kinase, squamous cell carcinoma

\section{Introduction}

The survival rate for patients with oral squamous cell carcinoma (OSCC) remains poor despite advances in diagnosis and treatment (1). OSCC usually develops in areas of carcinogen-exposed epithelium, and likely results from the accumulation of cellular and genetic alterations, leading to aberrant expression of proteins involved in cell growth regulation (2). Blocking or modifying the function of one or several of these proteins may impede or delay the development of cancer. Chemotherapy is the mainstay of treatment for patients with recurrent and/or metastatic OSCC, both alone and in combination with other agents or radiation therapy (3). Cisplatin/carboplatin, 5-fluorouracil, and paclitaxel/docetaxel are frequently used in combination therapies for the treatment of OSCC because their combined use results in a synergistic cytotoxic effect (4-7).

Apoptosis has been proposed to be an important mode of cell death in cancers treated with anticancer drugs $(8,9)$. These drugs act via a cascade of biochemical events, several of which eventually lead to apoptosis. In most cancer cells, apoptosis is dependent on an intact caspase cascade, and is mediated through the mitochondrial apoptosis pathway $(10-12)$. This apoptotic pathway is regulated by pro- and anti-apoptotic members of the Bcl-2 family of proteins (12). Once activated, certain caspases also fall under the control of inhibitor of apoptosis proteins (IAPs) (11). Alterations in the function of these apoptotic proteins contribute to resistance to chemotherapeutic agents $(12,13)$.

Intracellular mediators of apoptosis, while still largely unknown, are currently a subject of considerable interest and study. Phosphatidylinositol 3-kinase (PI 3-K) can control cell survival/death through the phosphorylation of Akt in cancer cells $(14,15)$, and the PI 3-K/Akt signaling pathway is now recognized as one of the most critical pathways in the regulation of cell survival. The activation of Akt-mediated signaling pathways provides cells with a survival signal that allows them to withstand apoptotic stimuli $(16,17)$. A great deal of evidence supports the idea that the major functions of Akt (also known as PKB) are to promote growth factormediated cell survival and block apoptosis. Activated Akt phosphorylates Bad, procaspase-9, forkhead, cyclic AMP 
response element-binding protein, and ІкB kinase, resulting in the suppression of apoptotic signaling and expression of antiapoptotic genes (18). However, the mechanism of attenuation of anticancer drug-mediated apoptosis by the PI 3-K/Akt signaling pathway is largely unclear.

New treatments for the management of OSCC patients are urgently needed. In a previous study, we demonstrated that treatment of OSCC cells with PI 3-K inhibitors enhanced their susceptibility to Fas-mediated apoptosis (19). This suggested that blocking PI 3-K/Akt signaling could be an effective anticancer therapy. In the current study, we investigated the molecular mechanism of tumor remission by examining the combined effect of PI $3-\mathrm{K}$ inhibitors plus cisplatin, 5-fluorouracil or docetaxel on apoptosis in OSCC cells. We examined whether PI 3-K inhibitors can affect the susceptibility of OSCC cells to anticancer drug-mediated apoptosis, and the expression of members of the Bcl-2 and IAP families of proteins. We demonstrated that inhibition of PI 3-K enhances anticancer drug-mediated apoptosis through the down-regulation of Bad phosphorylation, and of Bcl-2, cIAP-1 and XIAP expression, and up-regulation of Bax expression in OSCC cells.

\section{Materials and methods}

Reagents. Dulbecco's modified Eagle's medium (DMEM) and fetal bovine serum (FBS) were obtained from Gibco BRL (Gaithersburg, MD). Cisplatin, 5-fluororacil and docetaxel were obtained from Wako Pure Chemical Industries (Osaka, Japan). A MEBCYTO apoptosis kit, which uses FITC-conjugated annexin V, was purchased from MBL (Nagoya, Japan). Control antibodies were obtained from PharMingen (San Diego, CA). The caspase inhibitors VAD-FMK (caspase family inhibitor), DEVD-FMK (caspase-3 inhibitor), IETD-FMK (caspase-8 inhibitor), LEHD-FMK (caspase-9 inhibitor), and FA-FMK (negative control for FMK) were also purchased from MBL. All other chemicals were supplied by Sigma Chemical Co. (St. Louis, MO). The PI 3-K inhibitor wortmannin was obtained from Calbiochem (San Diego, CA), and LY 294002 was obtained from Cayman Chemical (Ann Arbor, MI). Anti-Akt, anti-phospho-Akt (p-Akt), anti-Bad and anti-p-Bad antibodies were purchased from Upstate Biotechnology (Lake Placid, NY). Anti-Bax, anti-cIAP-1, anti-cIAP-2 and anti-XIAP antibodies were obtained from R\&D Systems Inc. (Minneapolis, $\mathrm{MN}$ ), anti-Bak antibody was from Stressgen Biotechnology (Victoria, Canada), and anti-Bcl-2 and anti-Bcl-xL antibodies were from Santa Cruz Biotechnology (Santa Cruz, CA). Control antibodies (secondary antibodies) were obtained from PharMingen. All other chemicals were of analytical grade.

Cell lines and culture conditions. The human OSCC cell line HSC-2 was grown as adherent monolayers. HSC-2 cells were established from SCC of the oral cavity. Cells were maintained in DMEM supplemented with $10 \%$ inactivated FBS, $2 \mathrm{mM}$ L-glutamine, and antibiotics (100 U/ml penicillin and $100 \mu \mathrm{g} /$ $\mathrm{ml}$ streptomycin) at $37^{\circ} \mathrm{C}$ in a humidified atmosphere of $5 \%$ $\mathrm{CO}_{2}$. The concentration of wortmannin or LY294002 used in the current experiments was $500 \mathrm{nM}$ and $30 \mu \mathrm{M}$, respectively (19).
Proliferation assays. The cytotoxic effect of cisplatin, 5fluorouracil, and docetaxel in OSSC cells was evaluated using a proliferation assay. Cell proliferation was assessed using Cell Counting Kit-8 (Wako, Tokyo, Japan), which labels cellular DNA with a fluorescent reagent (20). Briefly, cells $\left(1 \times 10^{4} /\right.$ well $)$ were seeded into 96 -well plates and cultured for $24 \mathrm{~h}$ to allow them to adhere. Then, cells were incubated with a range of concentrations of single agents cisplatin (0$40 \mu \mathrm{M})$, 5-fluorouracil (0-160 $\mu \mathrm{M})$, and docetaxel (0-16 nM), for $24 \mathrm{~h}$ at $37^{\circ} \mathrm{C}$, respectively. After incubation, $10 \mu \mathrm{l}$ of a formazan-generating reagent, WST-8, was added to each well for $45 \mathrm{~min}$ at $37^{\circ} \mathrm{C}$. The absorbance of each well at $450 \mathrm{~nm}$ was then measured using a microplate reader.

Flow cytometry. The binding of annexin V-FITC was used as a sensitive method of measuring apoptosis, using a previously described procedure (21), with slight modifications. Briefly, OSCC cells $\left(1 \times 10^{7}\right.$ cells $\left./ \mathrm{ml}\right)$ were preincubated with or without PI 3-K inhibitor for $2 \mathrm{~h}$. Treated OSCC cells $\left(1 \times 10^{6}\right.$ cells $\left./ \mathrm{ml}\right)$ were exposed to cisplatin $(5 \mu \mathrm{M}), 5$-fluorouracil $(20 \mu \mathrm{M})$ or docetaxel ( $2 \mathrm{nM})$ for $24 \mathrm{~h}$, then harvested. The dose of anticancer drug used was determined by preliminary studies, and corresponded to the concentration at which there was approximately $25 \%$ inhibition of cell proliferation. Cells were then incubated for $15 \mathrm{~min}$ at room temperature in binding buffer (10 mM HEPES, $140 \mathrm{mM} \mathrm{NaCl}, 2.5 \mathrm{mM} \mathrm{CaCl}_{2}, \mathrm{pH} 7.4$ ) containing a saturating concentration of annexin V-FITC, according to the manufacturer's instructions. After incubation, the cells were pelleted and analyzed using a FACScan flow cytometer and Cell Quest software (Becton Dickinson Co., Mountain View, CA). Where indicated experiments were performed in the presence of caspase inhibitors $(20 \mu \mathrm{M})$.

Western blot analysis. Akt, p-Akt, Bad, p-Bad, Bax, Bak, Bcl-2, Bcl-xL, cIAP-1, cIAP-2 and XIAP expression were analyzed by Western blotting. OSCC cells $\left(1 \times 10^{7}\right.$ cells $\left./ \mathrm{ml}\right)$ were incubated with wortmannin $(500 \mathrm{nM})$ or LY294002 $(30 \mu \mathrm{M})$ for $2 \mathrm{~h}$ to analyze the expression of Akt and Bad, and for $12 \mathrm{~h}$ to analyze the expression of Bax, Bak, Bcl-2, Bcl-xL, cIAP-1, cIAP-2 and XIAP. After treatment, cells were pelleted and lysed in lysis buffer ( $\mathrm{pH} 7.4$ ) containing $50 \mathrm{mM}$ Tris- $\mathrm{HCl}, 300 \mathrm{mM} \mathrm{NaCl}, 5 \mathrm{mM}$ EDTA, $0.5 \%$ Triton X-100, $1 \mathrm{mM}$ PMSF, $10 \mu \mathrm{g} / \mathrm{ml}$ leupeptin and $20 \mu \mathrm{g} / \mathrm{ml}$ aprotinin. Of cellular protein, $60 \mu \mathrm{g}$ was separated on a $10 \% \mathrm{SDS}$ polyacrylamide gradient gel using the ECL Western blotting analysis system (Amersham Pharmacia Biotech, Piscataway, $\mathrm{NJ}$ ), according to the manufacturer's instructions and previously reported methods (19). Proteins were electrophoretically transferred to a nitrocellulose membrane, Immobilon-P (Millipore, Tokyo, Japan). After the membrane was incubated with $5 \%$ BSA, it was incubated with the indicated primary antibody, then with alkaline phosphatase-linked anti-rabbit or anti-mouse IgG secondary antibody (Amersham Pharmacia Biotech), and alkaline phosphatase-linked anti-biotin antibody (Amersham Pharmacia Biotech). Immunoreactive proteins were detected using an ECL detection reagent and captured on X-ray film. $\beta$-actin served as a positive control. Immunoreactive bands were analyzed using the FluoroImager 595 and ImageQuant software (Amersham Biosciences). Background levels were subtracted from each sample, and the protein level 


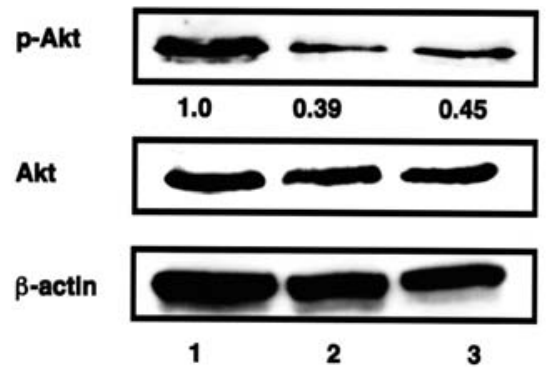

Figure 1. Effect of PI 3-K inhibitors on phosphorylation of Akt in HSC-2 cells. Western blot analysis of Akt and p-Akt from HSC-2 cells cultured in the presence of wortmannin $(500 \mathrm{nM})$ or LY294002 $(30 \mu \mathrm{M})$ for $2 \mathrm{~h}$. Expression and phosphorylation of Akt was analyzed as described in Materials and methods. Data is representative of four independent experiments. Lane 1, control; lane 2, wortmannin; lane 3, LY294002. p-Akt protein levels were analyzed by densitometry, and the p-Akt: $\beta$-actin ratio was calculated as described in Materials and methods. The ratio in control cells was set as 1.0.

in each sample was normalized to actin. The protein level in each of the treated samples was divided by the protein level in the control pre-treated sample to generate a value for the relative level of expression of each protein. The expression level in the control was given an arbitrary value of 1.0.

Statistical analysis. The data represents the means \pm standard deviation (SD). Differences between groups were analyzed using an unpaired two-tailed Student's t-test. A p-value of $<0.05$ was considered significant.

\section{Results}

Effect of PI 3-K inhibitors on Akt phosphorylation in OSCC cells. The PI 3-K/Akt signaling pathway controls cell survival in cancer cells $(14,15)$. To determine whether the PI 3-K inhibitors wortmannin and LY294002 reduced the activation of Akt in OSCC cells, we examined the phosphorylation of Akt in PI 3-K inhibitor-treated OSCC cells using Western blot analysis. In untreated OSCC cells, Akt was constitutively phosphorylated, reflecting the contribution of the PI 3-K/Akt pathway to cell survival. As shown in Fig. 1, phosphorylation of Akt was potentially down-regulated in the presence of wortmannin $(500 \mathrm{nM})$ and LY294002 $(30 \mu \mathrm{M})$. Thus, both of the PI 3-K inhibitors diminished Akt activity in OSCC cells. These results suggested that inhibition of PI 3-K modulates cell survival and/or cell death in OSCC cells.

Effect of anticancer drugs on cell proliferation in OSCC cells. Cisplatin, 5-fluorouracil and docetaxel are the most frequently used agents for the treatment of patients with SCC (4-7). To determine whether these anticancer drugs altered the proliferation of OSCC cells, we performed a preliminary analysis of the effect of cisplatin $(0-40 \mu \mathrm{M}), 5$-fluorouracil $(0-160 \mu \mathrm{M})$, and docetaxel $(0-16 \mathrm{nM})$ on the proliferation of HAS-2 cells, an OSCC cell line. We found that all three compounds inhibited OSCC cell growth in a dose-dependent manner (Fig. 2).

Effects of PI 3-K inhibitors on anticancer drug-mediated apoptosis in OSCC cells. Akt is constitutively activated and promotes cellular survival and resistance to chemotherapy in

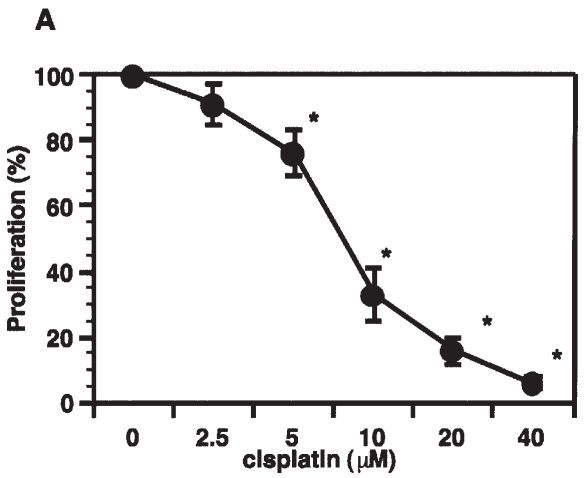

B

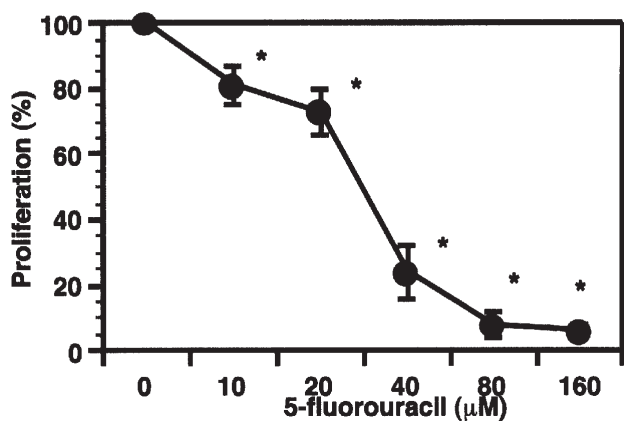

C

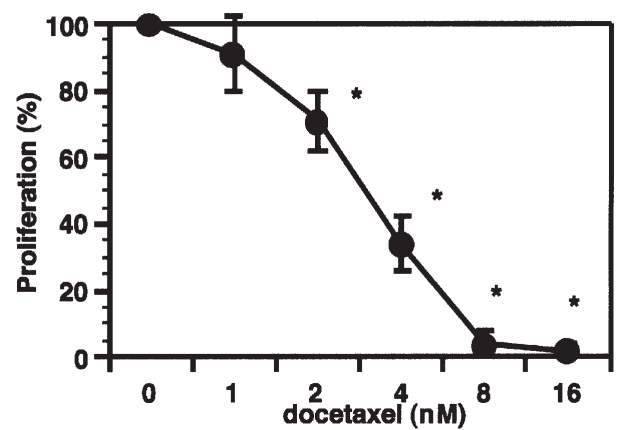

Figure 2. Effect of anticancer drugs on the proliferation of HSC-2 cells. Cell proliferation assay of HSC-2 cells cultured in the presence of cisplatin (0$40 \mu \mathrm{M})$, 5-fluorouracil $(0-160 \mu \mathrm{M})$, or docetaxel $(0-16 \mathrm{nM})$ for $24 \mathrm{~h}$. Cell proliferation was assayed as described in Materials and methods. Data represents the means $\pm \mathrm{SD}$ of four independent experiments. A, cisplatin; $\mathrm{B}, 5$-fluorouracil; C, docetaxel. " $\mathrm{p}<0.05$, compared with untreated cells in the absence of anticancer drugs.

cancer cells (22). To determine whether PI 3-K inhibitortreated OSCC cells had an altered susceptibility to anticancer drug-mediated apoptosis, we used a flow cytometer and the binding of annexin $\mathrm{V}$ to examine apoptosis in OSCC cells treated with PI 3-K inhibitors alone, a fixed dose of anticancer drug or a combination of PI 3-K inhibitor and anticancer drug. The doses of anticancer drug were $5 \mu \mathrm{M}$ cisplatin, $20 \mu \mathrm{M}$ 5-fluorouracil, and $2 \mathrm{nM}$ docetaxel. These concentrations corresponded to the doses at which $25 \%$ inhibition of cell growth was observed in cell proliferation experiments. Cells treated with a combination of anticancer drugs (cisplatin, 5-fluorourcil or docetaxel), and PI 3-K inhibitor showed significantly higher levels of apoptosis than those treated with PI 3-K inhibitor alone (Fig. 3). PI 3-K inhibitor-treated OSCC cells also exhibited higher levels of enhanced spontaneous 
A
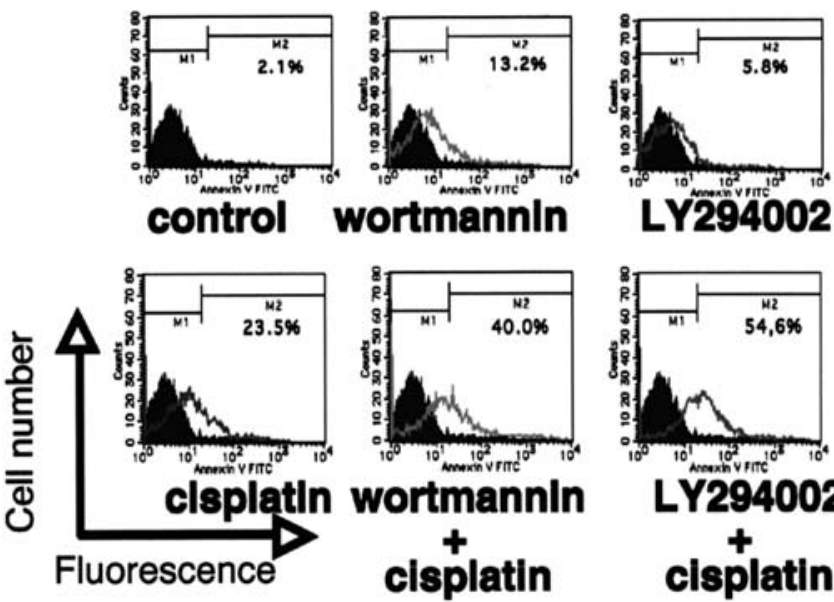

intensity

B
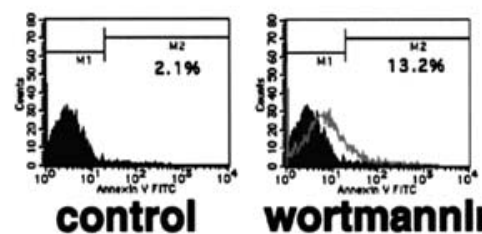
wortmannin
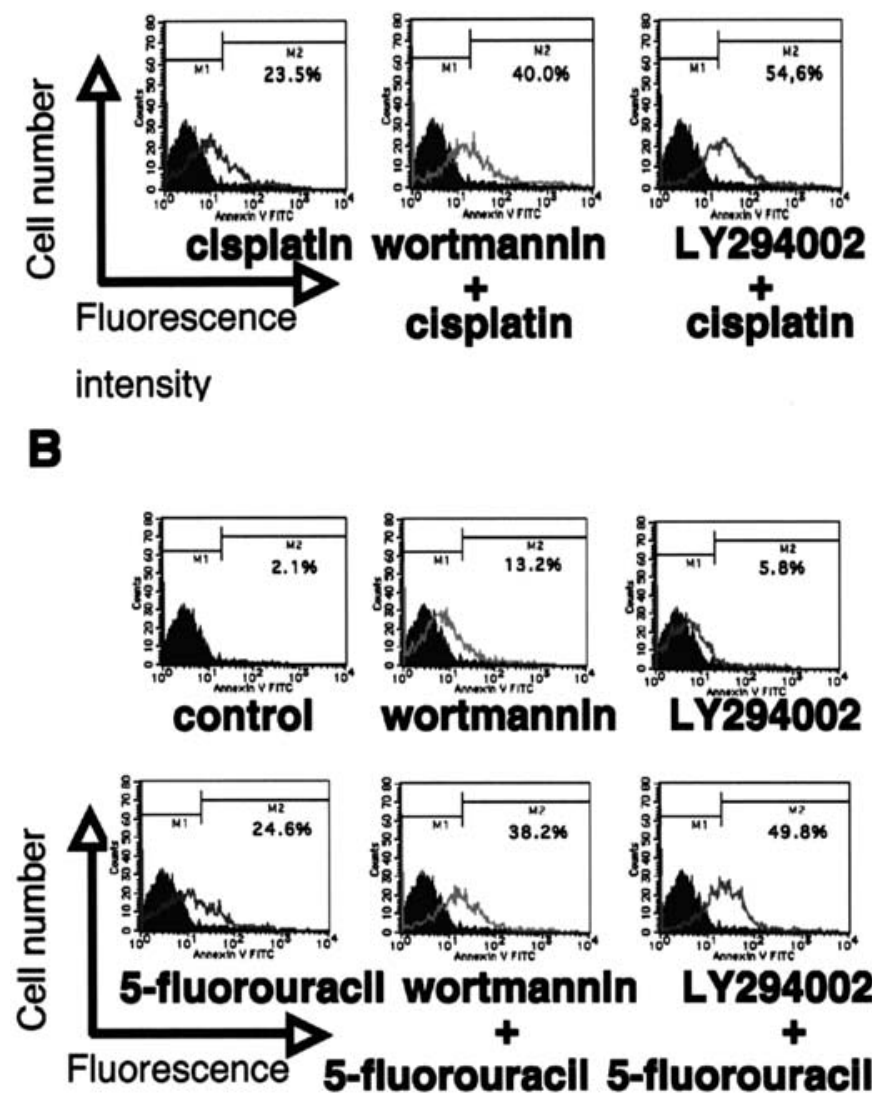

intensity
C

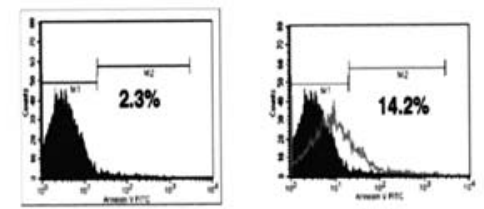

control wortmannin

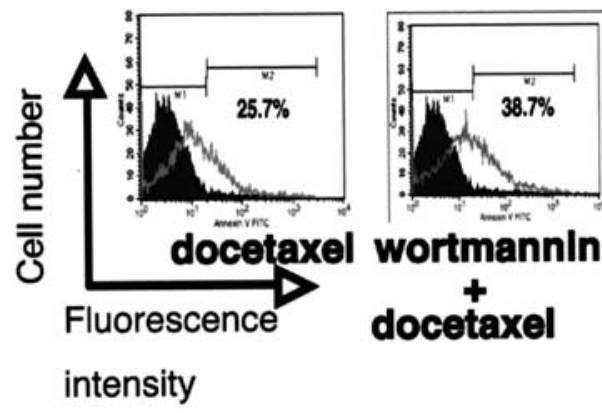

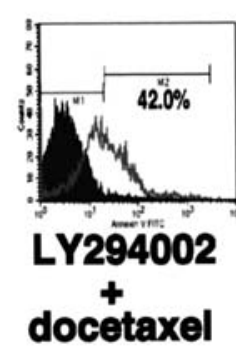

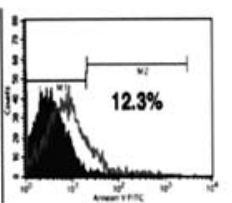

LY294002

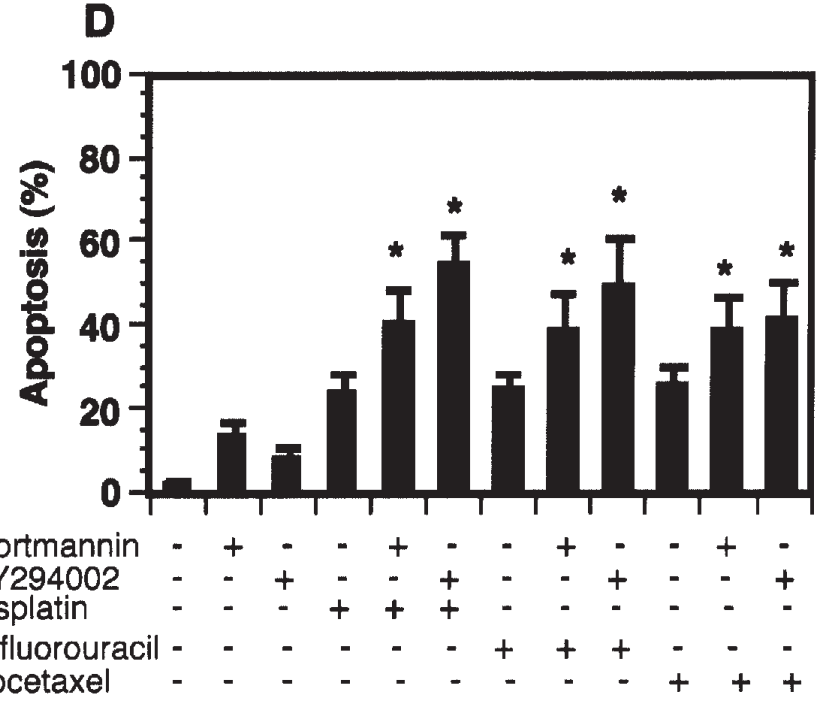

Figure 3. Effect of PI 3-K inhibitors on anticancer drug-mediated apoptosis in HSC-2 cells. Flow cytometry analysis of HSC-2 cells treated with or without wortmannin $(500 \mathrm{nM})$ or LY294002 $(30 \mu \mathrm{M})$ for $2 \mathrm{~h}$, then harvested and incubated with cisplatin $(5 \mu \mathrm{M}), 5$-fluorouracil $(20 \mu \mathrm{M})$ or docetaxel $(2 \mathrm{nM})$ for $24 \mathrm{~h}$. A, cisplatin; B, 5-fluorouracil; C, docetaxel. D, number of annexin V-positive cells. Dark and light lines indicate untreated controls and treated experimental cells, respectively. A-C are representative histograms, and D represents the means \pm SD of four independent experiments. ${ }^{*}<<0.05$, compared with untreated cells in the absence of PI 3-K inhibitor.

apoptosis compared to untreated OSCC cells (Fig. 3). However, the potentiating, pro-apoptotic effect of the PI 3-K inhibitors was strongly enhanced in the presence of the anticancer drugs. We next examined whether caspase inhibitors affected the proapoptotic activity of wortmannin and LY294002. Treatment of OSCC cells with a caspase family inhibitor (VAD), caspase-3 inhibitor (DEVD), or caspase-9 inhibitor (LEHD) reduced the potentiating effect of both of the PI 3-K inhibitors on anticancer drug-induced apoptosis, while treatment with the caspase-8 inhibitor (IETD) did not (Fig. 4). These results indicated that the pro-apoptotic action of wortmannin and LY294002 is mediated by caspase- 9 and -3 signaling pathways in OSCC cells.

Effect of PI 3-K inhibitors on Bad phosphorylation in OSCC cells. Phosphorylation of Bad causes disruption of protein complexes containing Bad and members of the Bcl-2 family of anti-apoptotic proteins, resulting in prolonged cell survival (18). We next examined whether wortmannin and LY294002 prevented the phosphorylation of Bad in OSCC cells. Both wortmannin $(500 \mathrm{nM})$ and LY294002 $(30 \mu \mathrm{M})$ markedly attenuated the phosphorylation of Bad in OSCC cells (Fig. 5). These results indicated that inhibition of PI 3-K blocks the Aktmediated cell survival pathway through the down-regulation of Bad phosphorylation in OSCC cells.

Effect of PI 3-K inhibitors on the expression of pro- and antiapoptotic proteins in OSCC cells. The apoptotic pathway is regulated by members of the Bcl-2 and IAP family of proteins $(11,12)$. To determine whether the expression of pro- and anti-apoptotic proteins in OSCC cells was altered by treatment with PI 3-K inhibitors, we examined the level of Bcl-2 family and IAP family proteins using Western blot analysis. Both of the PI 3-K inhibitors diminished the levels of the anti- 

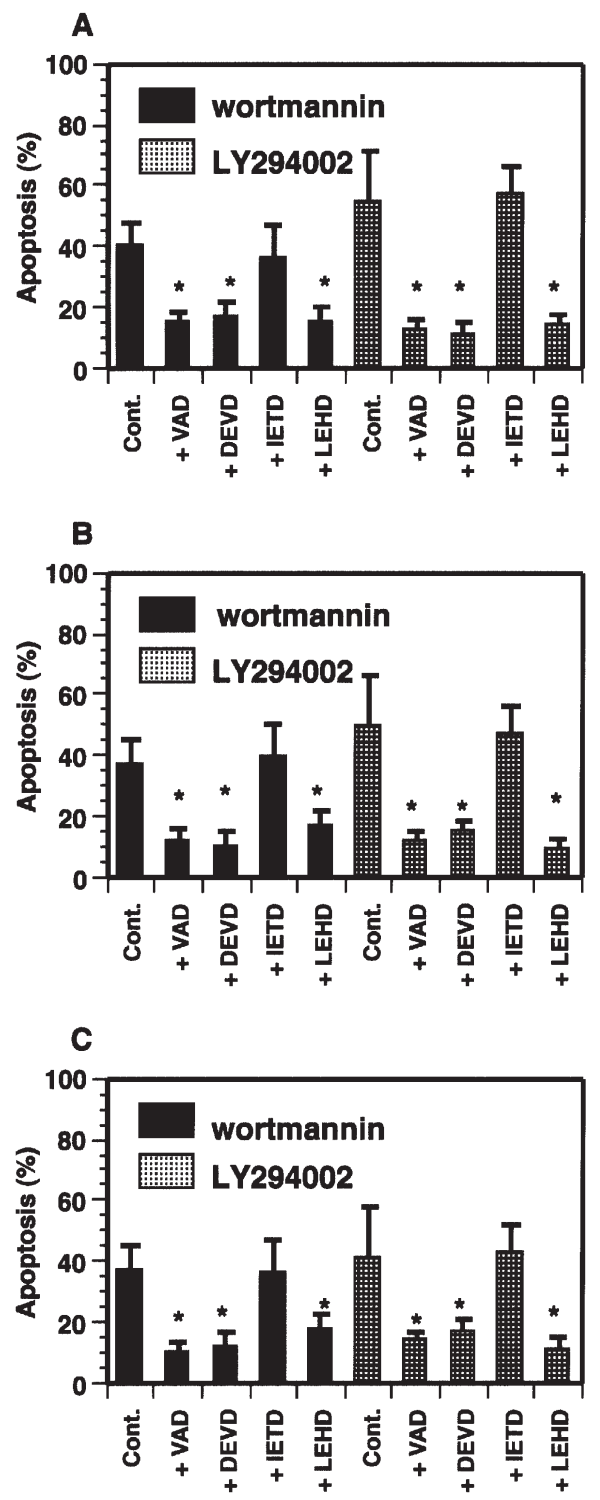

Figure 4. Effect of caspase inhibitors on anticancer drug-mediated apoptosis in HSC-2 cells treated with PI 3-K inhibitor and anticancer drugs. HSC-2 cells were treated with or without wortmannin $(500 \mathrm{nM})$ or LY294002 $(30 \mu \mathrm{M})$ for $2 \mathrm{~h}$, harvested, and incubated with cisplatin $(5 \mu \mathrm{M})$, 5-fluorouracil $(20 \mu \mathrm{M})$ or docetaxel $(2 \mathrm{nM})$ for $24 \mathrm{~h}$ in the presence of various caspase inhibitors $(20 \mu \mathrm{M})$. Cells were then analyzed as for Fig. 3 and the number of annexin V-positive cells is presented. A, cisplatin; B, 5-fluorouracil; C, docetaxel. Data represents the means \pm SD of four independent experiments. ${ }^{*} \mathrm{p}<0.05$, compared with untreated cells in the absence of caspase inhibitor.

apoptotic protein $\mathrm{Bcl}-2$, and the pro-apoptotic protein Bax. In contrast, the levels of Bcl-xL and Bak were not altered (Fig. 6A). Treatment with either wortmannin or LY294002 also diminished the levels of cIAP-1 and XIAP, while the level of cIAP-2 was unaltered (Fig. 6B). These results suggested that the PI 3-K/Akt pathway modulates anticancer drugmediated apoptosis through regulation of the expression of both pro- and anti-apoptotic proteins in OSCC cells.

\section{Discussion}

Several studies have shown that Akt is constitutively activated and promotes cellular survival and resistance to chemotherapy or ionizing radiation in cancer cells (22). It is also well known

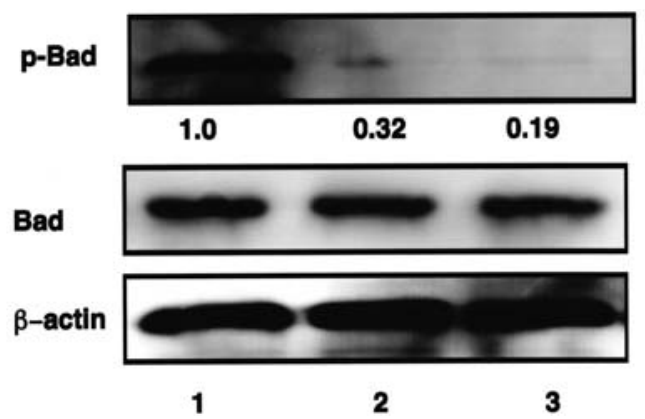

Figure 5. Effect of PI 3-K inhibitors on phosphorylation of Bad in HSC-2 cells. Western blot analysis of HSC-2 cells cultured in the presence of wortmannin $(500 \mathrm{nM})$ or LY294002 $(30 \mu \mathrm{M})$ for $2 \mathrm{~h}$. Cells were assayed for the expression and phosphorylation of Bad as described in Materials and methods. Data is representative of four independent experiments. Lane 1, control; lane 2, wortmannin; lane 3, LY294002. p-Bad protein levels were analyzed by densitometry, and the p-Bad:ß-actin ratio was calculated as for Fig. 1. The ratio in control cells was set as 1.0.

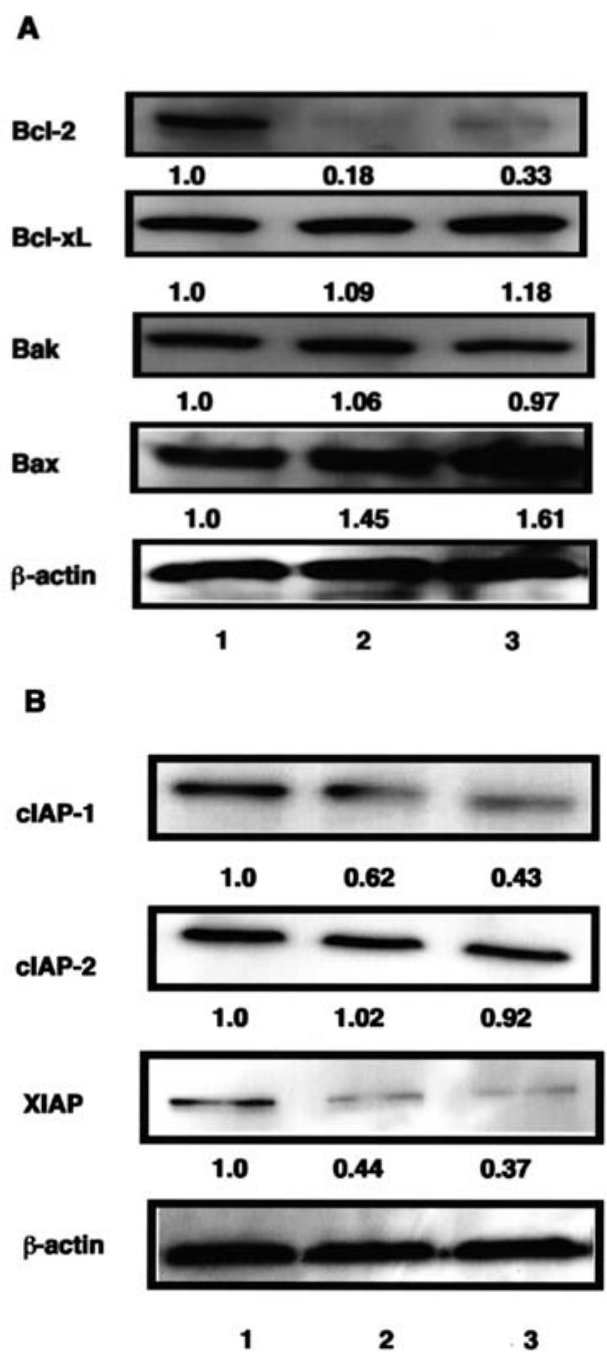

Figure 6. Effect of PI 3-K inhibitors on the expression of pro- and antiapoptotic proteins in HSC-2 cells. Western blot analysis of HSC-2 cells treated with wortmannin $(500 \mathrm{nM})$ or LY294002 $(30 \mu \mathrm{M})$ for $12 \mathrm{~h}$. Cells were assayed for the expression of the indicated proteins as described in Materials and methods. Data is representative of four independent experiments. A, Bcl-2 family proteins; B, IAP family proteins. Lane 1, control; lane 2, wortmannin; lane 3, LY294002. Protein levels were analyzed by densitometry, and the ratio of each protein to ß-actin was calculated as for Fig. 1. The ratio in control cells was set as 1.0 . 
that anticancer drugs and irradiation induce cell death in part by suppressing PI 3-K/Akt activation $(23,24)$. Many reports have shown the synergistic augmentation of anticancer drugs and PI 3-K inhibitors in carcinoma cells including OSCC cells $(25,26)$. These results suggest that a combination of anticancer drugs and PI 3-K inhibitors may provide an effective approach to inducing apoptosis in OSCC cells. However, the mechanism of apoptosis and the apoptotic machinery involved in combined therapies of anticancer drugs and PI 3-K inhibitors in cancer cells is unclear.

We showed that in OSCC cells, Akt is constitutively phosphorylated, indicating that Akt activation in OSCC cells contributes to cell survival. Treatment with two PI 3-K inhibitors, wortmannin and LY294002, markedly suppressed the phosphorylation of Akt in HSC-2 cells, an OSCC cell line, suggesting that OSCC cell survival is mediated by the PI 3-K/Akt pathway, and that PI 3-K inhibitors may also induce apoptosis in OSCC cells. PI 3-K inhibitors, such as wortmannin and LY294002, have previously been examined for their anti-tumor activities $(27,28)$. We were interested in whether the susceptibility of OSCC cells to anticancer drugmediated apoptosis was altered by treatment with PI 3-K inhibitors. We demonstrated that PI $3-\mathrm{K}$ inhibitor-treated OSCC cells had significantly enhanced levels of cisplatin-, 5-fluorouracil-, and docetaxel-mediated apoptosis. We also demonstrated that inhibitors of caspase- 3 or caspase- 9 reduced the potentiating effect of PI 3-K inhibitors on anticancer drug-induced apoptosis, suggesting that the pathways involved in apoptosis of cancer cells by the combined use of PI 3-K inhibitors and anticancer drugs are related to intrinsic pathways of cellular apoptosis. These results also agree with a previous study in which it was shown that caspase-9 is the principal initiating caspase in anticancer drug-induced apoptosis in OSCC cells (29). In the current study, wortmannin and LY294002 also inhibited Bad phosphorylation in OSCC cells. Phosphorylated Bad binds to mitochondrial Bcl-2 or Bcl-xL, preventing cytochrome c release and caspase- 9 activation (30). This result provides further evidence that the pro-apoptotic action of PI 3-K inhibitors is mediated by components of the intrinsic apoptotic pathway in OSCC cells.

It is well known that apoptosis is regulated by both proand anti-apoptotic proteins, including the Bcl-2 and IAP families of proteins $(11,12)$. For example, caspase- 9 activation is inhibited by anti-apoptotic members of the Bcl-2 family of proteins, including $\mathrm{Bcl}-2$ and $\mathrm{Bcl}-\mathrm{xL}$, and facilitated by the pro-apoptotic Bcl-2 family members, including Bax and Bak (31). In addition, active caspase- $3,-6,-7$ and -9 can be inhibited by members of the IAP family of proteins (32). The involvement of Akt in mediating down-regulation of proapoptotic Bcl-2 family proteins, or up-regulation of antiapoptotic IAP and Bcl-2 family proteins, has been demonstrated in some studies $(11,12)$. Inhibition of Akt phosphorylation is coupled with a significant decrease in anti-apoptotic Bcl-2 and Bcl-xL in SCC (33). Although previous studies have shown that expression of Bcl-2 family and IAP family members is regulated by PI 3-K inhibitors, these results vary according to cancer cell type (34-40). For example, in various cancer cells, PI 3-K inhibitors have been shown to decrease the expression of Bcl-2 (34-36), Bcl-xL (34,39), cIAP-1 $(38,40)$, cIAP-2 (37), XIAP $(37,40)$, and survivin $(38)$, and increase the expression of Bak (35), and Bax $(35,36,40)$. In the current study, we demonstrated that treatment of OSCC cells with PI 3-K inhibitors resulted in down-regulation of the expression of the anti-apoptotic proteins Bcl-2, cIAP-1 and XIAP, and upregulation of the expression of the pro-apoptotic protein Bax. The alteration in expression of these apoptosis-regulated proteins suggests that they may be involved in the mechanism of enhanced anticancer drug-mediated apoptosis by PI 3-K inhibitors in OSCC cells. Ultimately, it is necessary to study anticancer drug-mediated apoptosis using knockdown or overexpression of $\mathrm{Bcl}-2$ and IAP family proteins in cancer cells. Recently, it was shown that antisense molecules that reduced Bcl-2 (41) or XIAP (42) levels sensitized cancer cells to anticancer drug-induced apoptosis.

In conclusion, we found that inactivation of PI 3-K/Akt signaling induced anticancer drug-mediated apoptosis in OSCC cells through the regulation of Bcl-2 and IAP family members. Our results provide further support for the hypothesis that the PI 3-K/Akt signaling pathway is a potent mechanism of resistance in OSCC cells to conventional therapies, such as chemotherapy. Pharmacological inhibitors of the PI 3-K/Akt signaling pathway might overcome this. Furthermore, the efficacy of multiple anticancer drugs combined with PI 3-K inhibitors might be even more powerful compared with a single anticancer drug in OSCC cells. Because the combination of PI 3-K inhibitor and conventional anticancer drug could potentially result in clinical efficacy using lower doses of anticancer drugs, this combined therapy may reduce anticancer drug-related toxicity. Due to inherent difficulties with the stability, solubility, and toxicity of wortmannin and LY294002, efforts are being made to develop new inhibitors of the PI 3-K pathway. Success in this area was recently demonstrated, with a report on the development of a new PI 3-K inhibitor with strong anti-tumor activity against human cancer without toxic effects in clinical organs (43).

\section{References}

1. Forastiere AA, Koch W, Trotti A and Sidransky D: Head and neck cancer. N Engl J Med 345: 1890-1900, 2001.

2. Jefferies S and Foulkes WD: Genetic mechanisms in squamous cell carcinoma of the head and neck. Oral Oncol 37: 115-126, 2001

3. Herskovic A, Martz K, al-Sarraf M, et al: Combined chemotherapy and radiotherapy compared with radiotherapy alone in patients with cancer of the esophagus. N Engl J Med 326: 1593-1598, 1992.

4. Forastiere AA, Metch B, Schuller DE, et al: Randomized comparison of cisplatin plus fluorouracil and carboplatin plus fluorouracil versus methotrexate in advanced squamous-cell carcinoma of the head and neck: a Southwest Oncology Group study. J Clin Oncol 10: 1245-1251, 1992.

5. De Andres L, Brunet J, Lopez-Pousa A, et al: Randomized trial of neoadjuvant cisplatin and fluorouracil versus carboplatin and fluorouracil in patients with stage IV-M0 head and neck cancer. J Clin Oncol 13: 1493-1500, 1995.

6. Clark JI, Hofmeister C, Choudhury A, et al: Phase II evaluation of paclitaxel in combination with carboplatin in advanced head and neck carcinoma. Cancer 92: 2334-2340, 2001.

7. Schrijvers D, Van Herpen C, Kerger J, et al: Docetaxel, cisplatin and 5-fluorouracil in patients with locally advanced unresectable head and neck cancer: a phase I-II feasibility study. Ann Oncol 15: 638-645, 2004.

8. Hickman JA: Apoptosis induced by anticancer drugs. Cancer Metastasis Rev 11: 121-139, 1992.

9. Fisher DE: Apoptosis in cancer therapy: crossing the threshold. Cell 78: 539-542, 1994. 
10. Costantini P, Jacotot E, Decaudin D and Kroemer G: Mitochondrion as a novel target of anticancer chemotherapy. J Natl Cancer Inst 92: 1042-1053, 2000.

11. Hersey $P$ and Zhang XD: Overcoming resistance of cancer cells to apoptosis. J Cell Physiol 196: 9-18, 2003.

12. Kaufmann SH and Vaux DL: Alterations in the apoptotic machinery and their potential role in anticancer drug resistance. Oncogene 22: 7414-7430, 2003.

13. Gottesman MM: Mechanisms of cancer drug resistance. Ann Rev Med 53: 615-627, 2002.

14. Vivanco I and Sawyers CL: The phosphatidylinositol 3-kinase AKT pathway in human cancer. Nat Rev Cancer 2: 489-501, 2002.

15. Luo J, Manning BD and Cantley LC: Targeting the PI3K-Akt pathway in human cancer: rationale and promise. Cancer Cell 4: 257-262, 2003.

16. Song G, Ouyang $G$ and Bao S: The activation of Akt/PKB signaling pathway and cell survival. J Cell Mol Med 9: 59-71, 2005.

17. Yao R and Cooper GM: Requirement for phosphatidylinositol-3 kinase in the prevention of apoptosis by nerve growth factor. Science 267: 2003-2006, 1995.

18. Datta SR, Brunet A and Greenberg ME: Cellular survival: a play in three Akts. Genes Dev 13: 2905-2927, 1999.

19. Kondo G, Iwase M, Watanabe H, et al: Enhancement of susceptibility to Fas-mediated apoptosis in oral squamous cell carcinoma cells by phosphatidylinositol 3-kinase inhibitor. Oral Oncol 42: 745-752, 2006.

20. Watanabe $\mathbf{H}$, Iwase $\mathbf{M}$, Ohashi $\mathbf{M}$ and Nagumo $\mathbf{M}$ : Role of interleukin-8 secreted from human oral squamous cell carcinoma cell lines. Oral Oncol 38: 670-679, 2002.

21. Iwase M, Watanabe $H$, Kondo $G$, Ohashi $M$ and Nagumo M: Enhanced susceptibility of oral squamous cell carcinoma cell lines to Fas-mediated apoptosis by cisplatin and 5-fluorouracil. Int J Cancer 106: 619-625, 2003.

22. Brognard J, Clark AS, Ni Y and Dennis PA: Akt/protein kinase $\mathrm{B}$ is constitutively active in non-small cell lung cancer cells and promotes cellular survival and resistance to chemotherapy and radiation. Cancer Res 61: 3986-3997, 2001.

23. Nakashio A, Fujita N, Rokudai S, Sato S and Tsuruo T: Prevention of phosphatidylinositol 3'-kinase-Akt survival signaling pathway during topotecan-induced apoptosis. Cancer Res 60: 5303-5309, 2000.

24. Tenzer A, Zingg D, Rocha S, et al: The phosphatidylinositide 3'-kinase/Akt survival pathway is a target for the anticancer and radiosensitizing agent PKC412, an inhibitor of protein kinase C. Cancer Res 61: 8203-8210, 2001.

25. Hu L, Hofmann J, Lu Y, Mills GB and Jaffe RB: Inhibition of phosphatidylinositol 3'-kinase increases efficacy of paclitaxel in in vitro and in vivo ovarian cancer models. Cancer Res 62: 1087-1092, 2002.

26. Ohta T, Ohmichi M, Hayasaka T, et al: Inhibition of phosphatidylinositol 3-kinase increases efficacy of cisplatin in in vivo ovarian cancer models. Endocrinology 147: 1761-1769, 2006.

27. Lemke LE, Paine-Murrieta GD, Taylor CW and Powis G: Wortmannin inhibits the growth of mammary tumors despite the existence of a novel wortmannin-insensitive phosphatidylinositol3-kinase. Cancer Chemother Pharmacol 44: 491-497, 1999.
28. Semba S, Itoh N, Ito M, Harada M and Yamakawa M: The in vitro and in vivo effects of 2-(4-morpholinyl)-8-phenyl-chromone (LY294002), a specific inhibitor of phosphatidylinositol 3'-kinase, in human colon cancer cells. Clin Cancer Res 8: 1957-1963, 2002.

29. Kuwahara D, Tsutsumi K, Kobayashi T, Hasunuma T and Nishioka K: Caspase-9 regulates cisplatin-induced apoptosis in human head and neck squamous cell carcinoma cells. Cancer Lett 148: 65-71, 2000.

30. Kennedy SG, Kandel ES, Cross TK and Hay N: Akt/protein kinase $\mathrm{B}$ inhibits cell death by preventing the release of cytochrome c from mitochondria. Mol Cell Biol 19: 5800-5810, 1999.

31. Cory S and Adams JM: The Bcl2 family: regulators of the cellular life-or-death switch. Nat Rev Cancer 2: 647-656, 2002.

32. Salvesen GS and Duckett CS: IAP proteins: blocking the road to death's door. Nat Rev Mol Cell Biol 3: 401-410, 2002.

33. Sharma H, Sen S and Singh N: Molecular pathways in the chemosensitization of cisplatin by quercetin in human head and neck cancer. Cancer Biol Ther 4: 949-955, 2005.

34. Chen X, Thakkar H, Tyan F, et al: Constitutively active Akt is an important regulator of TRAIL sensitivity in prostate cancer. Oncogene 20: 6073-6083, 2001.

35. Panaretakis T, Pokrovskaja K, Shoshan MC and Grander D: Activation of Bak, Bax, and $\mathrm{BH} 3$-only proteins in the apoptotic response to doxorubicin. J Biol Chem 277: 44317-44326, 2002.

36. De Haes P, Garmyn M, Carmeliet G, et al: Molecular pathways involved in the anti-apoptotic effect of 1,25-dihydroxyvitamin D3 in primary human keratinocytes. J Cell Biochem 93: 951-967, 2004.

37. $\mathrm{Hu} \mathrm{P}, \mathrm{Han} \mathrm{Z}$, Couvillon $\mathrm{AD}$ and Exton JH: Critical role of endogenous Akt/IAPs and MEK1/ERK pathways in counteracting endoplasmic reticulum stress-induced cell death. J Biol Chem 279: 49420-49429, 2004.

38. Kim S, Kang J, Qiao J, Thomas RP, Evers BM and Chung DH: Phosphatidylinositol 3-kinase inhibition down-regulates survivin and facilitates TRAIL-mediated apoptosis in neuroblastoma. J Pediatr Surg 39: 516-521, 2004.

39. Alfano D, Iaccarino I and Stoppelli MP: Urokinase signaling through its receptor protects against anoikis by increasing BCL-XL expression levels. J Biol Chem 281: 17758-17767, 2006

40. Liu X, Shi Y, Giranda VL and Luo Y: Inhibition of the phosphatidylinositol 3-kinase/Akt pathway sensitizes MDAMB468 human breast cancer cells to cerulenin-induced apoptosis. Mol Cancer Ther 5: 494-501, 2006.

41. Campos L, Sabido O, Rouault JP and Guyotat D: Effects of BCL-2 antisense oligodeoxynucleotides on in vitro proliferation and survival of normal marrow progenitors and leukemic cells. Blood 84: 595-600, 1994.

42. Li J, Feng Q, Kim JM, et al: Human ovarian cancer and cisplatin resistance: possible role of inhibitor of apoptosis proteins. Endocrinology 142: 370-380, 2001.

43. Yaguchi S, Fukui Y, Koshimizu I, et al: Antitumor activity of ZSTK474, a new phosphatidylinositol 3-kinase inhibitor. J Natl Cancer Inst 98: 545-556, 2006. 